Published in final edited form as:

Schizophr Res. 2013 August ; 148(0): . doi:10.1016/j.schres.2013.05.019.

\title{
Psychotropic Medication Use in Youth at High Risk for Psychosis: Comparison of Baseline Data from Two Research Cohorts 1998-2005 and 2008-2011
}

\author{
Scott W. Woods, MD $^{1}$, Jean Addington, $\mathrm{PhD}^{2}$, Carrie E. Bearden, $\mathrm{PhD}^{3}$, Kristin S. \\ Cadenhead, MD ${ }^{4}$, Tyrone D. Cannon, PhD $^{5}$, Barbara A. Cornblatt, PhD ${ }^{6}$, Daniel H. \\ Mathalon, PhD MD ${ }^{7}$, Diana O. Perkins, MD $^{8}$, Larry J. Seidman, PhD $^{9}$, Ming T. Tsuang, MD \\ $\mathbf{P h D}^{4}$, Elaine F. Walker, $\mathbf{P h D}^{10}$, and Thomas H. McGlashan, $\mathbf{M D}^{1}$ \\ ${ }^{1}$ Department of Psychiatry, Yale University, New Haven CT \\ ${ }^{2}$ Department of Psychiatry, University of Calgary, Alberta, Canada \\ ${ }^{3}$ Departments of Psychiatry and Biobehavioral Sciences and Psychology, UCLA, Los Angeles CA \\ ${ }^{4}$ Department of Psychiatry, UCSD, San Diego CA \\ ${ }^{5}$ Department of Psychology, Yale University, New Haven CT \\ ${ }^{6}$ Department of Psychiatry, Zucker Hillside Hospital, Long Island NY \\ ${ }^{7}$ Department of Psychiatry, UCSF, San Francisco CA \\ ${ }^{8}$ Department of Psychiatry, University of North Carolina, Chapel Hill NC \\ ${ }^{9}$ Department of Psychiatry, Harvard Medical School at Beth Israel Deaconess Medical Center and \\ Massachusetts General Hospital, Boston MA \\ ${ }^{10}$ Departments of Psychology and Psychiatry, Emory University, Atlanta GA
}

\section{Abstract}

(C) 2013 Elsevier B.V. All rights reserved.

*Corresponding author at: Connecticut Mental Health Center, Yale University School of Medicine, 34 Park Street, New Haven CT USA 06519. scott.woods@yale.edu (S. Woods)..

Publisher's Disclaimer: This is a PDF file of an unedited manuscript that has been accepted for publication. As a service to our customers we are providing this early version of the manuscript. The manuscript will undergo copyediting, typesetting, and review of the resulting proof before it is published in its final citable form. Please note that during the production process errors may be discovered which could affect the content, and all legal disclaimers that apply to the journal pertain.

Conflict of interest Dr. Woods reports that within three years of beginning this work he has received investigator-initiated research funding support from UCB Pharma, Eli Lilly, Janssen, Pfizer, and Bristol-Myers Squibb and has consulted to Otsuka and ScheringPlough. He has also served as an unpaid consultant to DSM-5. Drs. Addington, Bearden, and Cadenhead report no actual or potential conflict of interest. Dr. Cannon reports that within three years of beginning this work he has served as a consultant for Janssen Pharmaceuticals and Eli Lilly. Dr. Cornblatt reports that within three years of beginning this work she has served as a consultant for Lilly, Bristol-Meyers Squibb and Janssen Pharmaceuticals and has received unrestricted educational grants from Janssen. Dr. Mathalon reports that within three years of beginning this work he has served as a consultant a consultant for Bristol-Myers Squibb. Dr. Perkins reports reports that within three years of beginning this work she has received received research funding from AstraZeneca Pharmaceuticals LP, Bristol-Myers Squibb, Otsuka Pharmaceutical Co. Ltd, Eli Lilly and Co., Janssen Pharmaceutica Products, and Pfizer Inc.; and consulting and educational fees from AstraZeneca Pharmaceuticals LP, Bristol-Myers Squibb, Eli Lilly and Co., Janssen Pharmaceuticals, GlaxoSmithKline, Forest Labs, Pfizer Inc, and Shire. Drs. Seidman, Tsuang, and Walker report no actual or potential conflict of interest. Dr. McGlashan reports that within three years of beginning this work he has received investigatorinitiated research funding support from Eli Lilly Company. He has also served as a consultant for Lilly, Pfizer, Solvay/Wyeth, and Roche pharmaceuticals and as an unpaid consultant to DSM-5.

Contributors All authors contributed to the designs of the NAPLS-1 and/or NAPLS-2 studies. Dr Woods took the lead on analyzing the data and writing the first draft. All authors contributed to and approved the final manuscript. 
Background-Antipsychotic medication use rates have generally been rising among youth with psychiatric disorders, but little is known about use rates of antipsychotics or other psychotropic medications in patients at high risk for psychosis.

Method-Baseline psychotropic medication use rates were compared in two research cohorts of patients at high risk for psychosis that enrolled between 1998-2005 $(\mathrm{n}=391)$ and 2008-2011 $(n=346)$. Treatment durations and antipsychotic doses were described for cohort 2.

Results-Median age was 17 years in cohort 1 and 18 years in cohort 2 . The rate of prescription of any psychotropic at baseline was roughly $40 \%$ for each cohort. Antipsychotic prescription rates were $24 \%$ among sites that permitted baseline antipsychotic use in cohort 1 and $18 \%$ in the cohort 2 ; the decline did not quite reach statistical significance $(\mathrm{p}=0.064)$. In cohort 2 the mean $\pm \mathrm{sd}$ baseline chlorpromazine-equivalent dose was $121 \pm 108 \mathrm{mg} / \mathrm{d}$, and lifetime duration of antipsychotic treatment was $3.8 \pm 5.9$ months.

Discussion-Although the rate of antipsychotic prescription among high-risk youth may have fallen slightly, the nearly one-in-five rate in the second cohort still constitutes a significant exposure. Mitigating factors were that doses and durations of treatment were low. As for other nonpsychotic conditions, it is incumbent on our field to develop alternative treatments for highrisk patients and to generate additional evidence for or against the efficacy of antipsychotics to help define their appropriate role if alternative treatments fail.

\section{Keywords}

psychosis; high risk; risk syndrome; psychotropic medication; antipsychotic medication

\section{Introduction}

Antipsychotic prescription in adolescents increased approximately four-fold in the US between 1993-1998 and 1999-2004 and then another roughly 40\% by 2005-2009 (Olfson et al., 2012). Use in adolescents in Canada has also increased (Pringsheim et al., 2011), and similar findings have been reported from Europe (Zuddas et al., 2011). The change does not primarily represent increased use for psychotic disorders; rather the increase is mostly or entirely seen in non-psychotic patients (Olfson et al., 2012; Pringsheim et al., 2011). Some antipsychotic medications do have FDA-approved uses in non-psychotic disorders (Christian et al., 2012), particularly for children and adolescents. Antipsychotic use has been rising in adult patients also (Alexander et al., 2011; Maher et al., 2011), but the increase may be of especial concern in youth since metabolic adverse effects appear even more frequent in young patients (Gebhardt et al., 2009; Kryzhanovskaya et al., 2012; Safer, 2011; Woods et al., 2002).

The risk syndrome for psychosis (Woods et al., 2009) is a non-psychotic condition under increasing investigation over the past two decades (Fusar-Poli et al., 2013; Klosterkoetter et al., 2011). Also known by other names including 'at-risk mental state' and 'ultra-high-risk', the risk syndrome is based on earlier retrospective observations of subsyndromal or "attenuated" positive symptoms in the months or years preceding frank onset of schizophrenia (Yung and McGorry, 1996a). A recent meta-analysis of 27 studies suggested that the average prospective rate of transition to frank psychosis is $22 \%$ by one year and $36 \%$ by three years (Fusar-Poli et al., 2012a). In addition to carrying substantial risk for psychosis, risk syndrome patients meet general mental health standards for current illness (Ruhrmann et al., 2010) in that at presentation they display distressing current symptoms and functional and cognitive impairment (Fusar-Poli et al., 2012b; Giuliano et al., 2012; Seidman et al., 2010; Woods et al., 2001; Woods et al., 2010b). Risk syndrome patients often qualify for comorbid diagnoses of other disorders (Addington et al., 2007; Addington 
et al., 2012; Rosen et al., 2006), and such comorbidities represent additional targets for treatment. Intervention studies have begun to address these patients' prevention and treatment needs (Stafford et al., 2013). Medication treatment studies have primarily focused on antipsychotics (McGlashan et al., 2006; McGorry et al., 2002; Ruhrmann et al., 2007; Woods et al., 2003; Woods et al., 2007; Yung et al., 2011) but have also included a search for alternative treatments with fewer adverse effects (Amminger et al., 2010).

Risk syndrome patients often seek and receive mental health treatment in the community (Cadenhead et al., 2010; Preda et al., 2002). The rates at which antipsychotic treatment occurs, and whether such rates are increasing, are therefore of clinical and public health interest. In the absence of epidemiologic studies, we report on community prescription of antipsychotics at baseline in two large research cohorts that recruited from 1998-2005 and 2008-2011. Prescription rates for other psychotropic medications are also included for comparison purposes.

\section{Methods}

The two research cohorts were ascertained by the North American Longitudinal Prodrome Study (NAPLS) group and are referred to as NAPLS-1 and NAPLS-2. Subjects under age 18 with schizotypal personality disorder (SPD) are included along with risk syndrome patients in both cohorts because evidence showed that youth with SPD were at high risk for psychosis as well, even when risk syndrome criteria were not met (Woods et al., 2009). The two groups of subjects together are referred to here as high-risk subjects.

\subsection{Design, subjects, and medication methods in NAPLS-1}

The NAPLS- 1 study reported on 377 risk syndrome subjects at baseline (Woods et al., 2009) and 36 subjects with SPD under age 18 who did not meet risk syndrome criteria, for a total of 413 high-risk patients. Subjects enrolled between 1998 and 2005. Methods have previously been reported in detail (Addington et al., 2007). Briefly, seven mostly independent projects with broadly similar goals focused on prospectively determining outcomes of a risk syndrome diagnosis and an eighth project collecting a sample of familial high-risk subjects created a federated database. Each site utilized the Structured Interview for Psychosis-risk Syndromes (SIPS) to determine whether risk syndrome or SPD criteria were met. The SIPS adopted and adapted three sets of criteria originally articulated by the Melbourne group (Yung et al., 1996b). Detailed descriptions of SIPS symptom severity scales, risk syndrome diagnostic criteria, and psychometric properties are available (Addington et al., 2007; Addington et al., 2012; Hawkins et al., 2004; Lemos et al., 2006; Lencz et al., 2004; Lencz et al., 2003; McGlashan et al., 2010; Miller et al., 2003; Miller et al., 2002; Woods et al., 2009). Some sites in NAPLS-1 did not permit or usually did not permit subjects on antipsychotic to enroll (UNC, Toronto, Yale); the remaining sites accepted patients without regard to baseline antipsychotic use. No other psychotropic medications were exclusionary for any site. Current psychotropic medication at baseline was recorded, but no information on doses or duration. Baseline medications in the NAPLS-1 cohort have been reported previously (Cadenhead et al., 2010; Walker et al., 2009).

\subsection{Design, subjects, and medication methods in NAPLS-2}

The ongoing NAPLS-2 study intends to enroll 720 high-risk subjects, and the first 360 enrolled are designated as the first half sample. Subjects in the first half sample were enrolled from late 2008 to early 2011, including 344 risk syndrome subjects and 16 subjects with SPD under age 18 who did not meet risk syndrome criteria. Methods for NAPLS-2 have also been described in detail (Addington et al., 2012). All sites followed a uniform protocol for enrollment and assessment, but sites were permitted to employ ascertainment 
strategies that worked best locally. One site moved from Toronto to Calgary between NAPLS-1 and NAPLS-2, keeping the same principal investigator, and the Harvard site began enrolling high-risk patients with NAPLS-2; otherwise the same sites participated in both cohorts. All sites in NAPLS-2 permitted patients to enroll without regard to baseline psychotropic medication. Patient enrollment required a consensus on a SIPS risk syndrome diagnosis among conference call participants from each site. Patients and/or parents were interviewed about any psychotropic medication prescribed since birth and periods of no medication. For each medication course we collected start date, stop date, medication name, daily dose if routine, and unit dose and frequency of use if as-needed. When the patient could not remember names of medications or doses, every effort was made to obtain the information from prescribers, medical records, and pharmacies. Individual courses were then summed to obtain duration data and chlorpromazine-equivalent doses (Woods, 2003) were calculated.

\subsection{Data analysis}

Demographic and diagnostic measures common to the two studies that might confound medication use rates across cohorts were selected for sample comparisons (Table S1 in Supplementary Content). Analyses used SPSS, version 19. Univariate comparisons utilized chi-square for categorical measures. One-sample Kolgorov-Smirnov (K-S) tests showed that none of the continuous measure distributions were normal. For these measures samples were therefore summarized using median and range and compared using the K-S Z statistic.

Effects of demographic and diagnostic measures on medication use rates were evaluated in the combined samples using Pearson correlations, or nominal regression when characteristics were multinominal. Nominal regression models would not converge for race, and Pearson correlations with a bivariate minority vs Caucasian variable were substituted. Logistic regression was used for multivariate comparisons of current medication at baseline between NAPLS-1 and NAPLS-2 cohorts, including as covariates demographic or diagnostic measures associated with specific medication use at $\mathrm{p}<0.05$. When age and age $<18$ were both associated with medication use, the variable with the larger absolute $r$ value was included in the model.

\section{Results}

\subsection{Participants and medication use rates}

Twenty-two patients in NAPLS-1 and fourteen in NAPLS-2 were missing baseline medication information (Table S1). The highest medication use rates (Table 1) in both cohorts were for antidepressants, followed by antipsychotics. Antipsychotic data by site (Table S2) confirmed that differences in inclusion/exclusion criteria between the two cohorts at three sites confounded a determination of change between cohort. Moreover, since antipsychotic use was correlated with antidepressant use, mood stabilizer use, and use of any and $>1$ psychotropic within the four sites whose inclusion/exclusion policy did not change (UCLA, Emory, Hillside, UCSD, Table S3), other medication use appeared confounded as well. Accordingly, for analyses of change in medication use rates across cohort sites were restricted to these four "qualifying sites."

At the four qualifying sites NAPLS-2 patients were more than a year older than those in NAPLS-1 (Table 2) and appeared to show a higher proportion of minority races (see Supplementary Content). Meeting inclusion criteria as a young SPD patient was less frequent than in NAPLS-1. Rates of comorbid bipolar were higher, anxiety disorders were slightly higher, and non-bipolar depression and ADD were lower at the four sites in NAPLS-2 relative to NAPLS-1. Generally these cohort differences at the qualifying sites 
were similar to those in the full samples, although in the full samples differences for anxiety disorder rates were statistically significant and those for ADD were not (Table S1).

\subsection{Correlates of psychotropic medication use in the combined samples}

Effects of site were statistically significant for antipsychotics and stimulants (Table S4). Younger patients were more likely to receive stimulants and polypharmacy. Minority race patients were less likely to use any psychotropic medication, antidepressants, mood stabilizers, and polypharmacy compared to Caucasians. Patients with lower GAF received antidepressants and polypharmacy more frequently. The SPD inclusion diagnosis was associated with stimulant use. Bipolar comorbidity was associated with mood stabilizer use, nonbipolar depression with antidepressant and stimulant use, anxiety comorbidity with benzodiazepine use, and ADD with stimulant use. Correlations among demographic and diagnostic predictors are shown in Table S5. Baseline psychotropic use rates were similar in NAPLS-2 at the qualifying sites (Table 3) and in the full sample (Table 1).

\subsection{Comparison of baseline psychotropic medication use across cohort}

Logistic regression models including covariates as described revealed lower rate ratios in NAPLS-2 relative to NAPLS- 1 for any psychotropic medication and polypharmacy, with trends toward reduced antipsychotic $(\mathrm{p}=0.064)$ and antidepressant use $(\mathrm{p}=0.057)$. For stimulants, mood stabilizers, and benzodiazepines confidence intervals overlapped unity.

The proportion of aripiprazole use increased between NAPLS-1 and NAPLS-2, and proportions for risperidone and olanzapine declined (Table 4). Four new antipsychotics had been marketed in the US since the NAPLS-1 cohort closed, paliperidone (2006), iloperidone (2009), asenapine (2009), and lurasidone (2010), but no patient in NAPLS-2 received them. Although in general the correlation between any antipsychotic use and comorbid nonbipolar depression was not statistically significant (Table S4), in the NAPLS-2 sample aripiprazole prescription correlated with comorbid nonbipolar depression $(\mathrm{r}=0.330, \mathrm{p}=0.009, \mathrm{n}=61)$. This correlation was not statistically significant for any other individual antipsychotic, including quetiapine $(\mathrm{r}=-0.059, \mathrm{p}=0.649, \mathrm{n}=61)$.

\subsection{Baseline antipsychotic doses}

Antipsychotic dose information was not collected in NAPLS-1. In NAPLS-2 the average chlorpromazine-equivalent baseline dose was $121 \mathrm{mg} / \mathrm{d}$ (Table 5). The correlation of baseline dose with duration was not statistically significant $(r=0.158, p=0.219, n=62)$. The chlorpromazine-equivalent dose in patients who had received antipsychotics for at least two months was slightly higher at $155 \pm 137 \mathrm{mg} / \mathrm{d}(\mathrm{n}=28)$.

\subsection{Lifetime psychotropic use among patients with use at baseline}

The longest lifetime duration of medication use were observed in patients receiving stimulants (Table 6). Duration of antidepressant and mood stabilizer use averaged about 18 months, benzodiazepine use about one year, and antipsychotic use about 4 months.

\subsection{Lifetime psychotropic use before first antipsychotic start}

More than half of patients on antipsychotics at baseline had received psychotropic medication from another class prior to receiving first lifetime antipsychotic (Table 7). Nearly half had received an antidepressant, for an average of roughly a year.

\subsection{Findings restricted to risk syndrome cases}

To facilitate comparisons with international cohorts, versions of Tables 3-7 are included in the Supplementary Content that restrict the high risk sample to risk syndrome cases and 
exclude the young SPD cases (Tables S6-10). Findings are similar to those of the primary analyses.

\section{Discussion}

The principal finding of the current study is that between 2008 and 2011 nearly one patient in five at high risk for psychosis was currently being prescribed antipsychotic medication in the community at the time of presentation to a North American research clinic. Compared to a previous cohort at the same sites from 1998 to 2005, this proportion had tended to fall. The pattern of specific medication shifted toward antipsychotics with less frequent metabolic side effects. Antipsychotic doses were relatively low, the duration of exposure to antipsychotics was brief relative to duration of exposure to other psychotropic medication classes, and in many cases an antidepressant medication trial appeared to have preceded antipsychotic prescription.

It is difficult to be certain why antipsychotic use rates have increased for other nonpsychotic conditions but did not increase for high-risk patients and may have dropped. Possibly prescribers are more aware of published treatment guidelines (reviewed in Woods et al, 2010b) discouraging antipsychotic use in risk syndrome patients. Although such a mechanism would not explain reduced antidepressant use (Table 3), an antidepressant effect could be related to 2004-2007 regulatory "black-box" warnings about antidepressants and suicidality in children (Busch and Barry, 2009) and young adults. Both antipsychotic and antidepressant medication reductions might have been affected by reports of treatment success with cognitive behavior therapy (Stafford et al., 2013).

By the time of NAPLS-2, aripiprazole had become the most frequently selected antipsychotic by the community prescribers, and risperidone and olanzapine use share had each fallen by more than half (Table 4). Although the rate of aripiprazole prescription in NAPLS-1 was limited by its late 2002 approval toward the end of cohort accrual, we speculate that these changes suggest community prescribers may have been seeking to reduce metabolic risks of prescription in these patients, since aripiprazole is generally regarded as yielding lower rates of such complications than olanzapine or risperidone (Cohen et al., 2012; Correll et al., 2009; De Hert et al., 2011). The metabolic profile of ziprasidone may indicate yet lower risk than aripiprazole (Cohen et al., 2012; De Hert et al., 2011), but for unknown reasons the relative proportion of use did not increase substantially between our two cohorts. Another possibility for the higher proportion of aripiprazole in NAPLS-2 is its late 2007 FDA approval as an adjunct to antidepressants. This possibility is supported by the correlation with comorbid depression (section 3.3). A similar indication for quetiapine in December 2009 may have come too late to have a similar effect.

Antipsychotic doses were relatively low (Table 5). The mean chlorpromazine-equivalent dose of $121 \mathrm{mg} / \mathrm{d}$ is lower than the $200 \mathrm{mg} / \mathrm{d}$ minimum effective dose in studies of established schizophrenia (Woods, 2003). Risk syndrome patients in an open-label aripiprazole trial (Woods et al., 2007) and in an olanzapine vs placebo study (Woods et al., 2003) received higher doses than shown here. The current low doses would have the advantage of minimizing adverse effects, but could possibly be associated with diminished efficacy as well. On the other hand, there is evidence that low doses of antipsychotic can produce large effect sizes in risk syndrome patients (Ruhrmann et al., 2007).

The primary limitation of the present studies is the uncertain ability to generalize from rates of medication prescribed at baseline in research studies to community prescription rates, since patients who volunteer for research studies can differ from their peers who do not (Woods et al., 2000). In addition, analyses of change in medication use rates had to be 
restricted to only four of the eight sites, which further limits generalizability. Lastly, we cannot rule out that procedural changes from NAPLS-1 to NAPLS-2, such as the diagnostic consensus requirement, could have influenced sample characteristics. These considerations underscore the need for epidemiologic sampling in future studies to obtain unbiased estimates.

Our data suggest several factors that may somewhat mitigate concerns about antipsychotic adverse effects in this population: rates did not increase and may have decreased, doses and durations of treatment were low, lower-risk antipsychotics were preferred, and other medication classes were often tried first. Still, it must be stated that the $18 \%$ rate of baseline antipsychotic prescription seen in the recent NAPLS-2 study is substantial. If high-risk patients across North American communities are receiving antipsychotics at comparable rates, it would constitute a significant exposure. At present the only placebo-controlled evidence for or against benefit to support such exposure is a single small study of olanzapine, which showed a statistically significant short-term symptomatic benefit but no significant functional benefit (Woods et al., 2003) and only a statistical trend toward prevention or delay of psychosis over one year (McGlashan et al., 2006).

For other nonpsychotic conditions the situation is similar. A recent meta-analysis identified 32 placebo-controlled trials of antipsychotics for various nonpsychotic conditions in adolescents (Zuddas et al., 2011) which in aggregate provide support for adolescent efficacy in some of the conditions for which they are used clinically. The database is limited, however, because many of the studies tended to be small and most followed patients only over the short term. The limitations in the efficacy database and the well-known adverse event profiles of antipsychotics have led some to label the increased use of these medications over the past 15 years as "overuse" (Frances, 2011). One of the main reasons that a risk syndrome diagnosis will not be included as a coded diagnosis in the new $5^{\text {th }}$ edition of the American Psychiatric Association's Diagnostic and Statistical Manual (under the name Attenuated Psychosis Syndrome (Carpenter and van Os, 2011)) was concern that it might result in inappropriate treatments (Regier, 2012). Given the substantial adverse effects of antipsychotics (Smith et al., 2008; Woods et al., 2010a), including the possibility of changes in brain gray matter (Radua et al., 2012), it is incumbent on our field to develop alternative treatments for high-risk patients (Amminger et al., 2010; Stafford et al., 2013) and also to generate additional evidence for or against the efficacy of antipsychotics in highrisk patients to define their appropriate role if alternative treatments fail.

\section{Supplementary Material}

Refer to Web version on PubMed Central for supplementary material.

\section{Acknowledgments}

J Stowkowy, T Raedler, L McGregor, D Marulanda, L Legere, L Liu, C Marshall, E Falukozi, E Fitton, and K Smith (University of Calgary). T Alderman, K Shafer, I Domingues, and A Hurria, H Mirzakhanian (UCSD). B Walsh, J Saksa, N Santamauro, A Carlson, J Kenney, and B Roman (Yale University). K Woodberry, AJ Giuliano,W Stone, JM Rodenhiser, L Tucker, R Serur, G Min, and R Szent-Imrey (Beth Israel Deaconess Medical Center/Harvard). C Bearden, P Bachman, J Zinberg, S DeSilva, A Andaya, and S Uguryan (UCLA). J Brasfield, and H Trotman (Emory University). A Pelletier, K Lansing, H Mates, J Nieri, B Landaas, K Graham, E Rothman, J Hurta, and Y Sierra (University of North Carolina). A Auther, R Carrion, M McLaughlin, and R Olsen (Zucker Hillside Hospital).

Role of the funding source This study was supported by the National Institute of Mental Health (grants U01 MH066160 and U01 MH082022 to Dr Woods; grants U01 MH066134 and U01 MH081984 to Dr Addington; grants U01 MH060720, R01 MH60720, U01 MH082022 and K24 MH76191 to Dr Cadenhead; grants U01 MH065079 and MH081902 to Dr Cannon; grants U01 MH061523 and U01 MH081857 to Dr Cornblatt; grants U01 MH066069 and U01 MH082004 to Dr Perkins; grants U01 MH065562, U01 MH081928, P50 MH080272 and 
Commonwealth of Massachusetts SCDMH82101008006 to Dr Seidman; and grants U01 MH062066 to EFW and U01 MH081988 to Dr Walker). The NIMH had no further role in study design; in the collection, analysis and interpretation of data; in the writing of the report; or in the decision to submit the paper for publication.

\section{References}

Addington J, Cadenhead KS, Cannon TD, Cornblatt B, McGlashan TH, Perkins DO, Seidman LJ, Tsuang M, Walker EF, Woods SW, Heinssen R. North American Prodrome Longitudinal Study: a collaborative multisite approach to prodromal schizophrenia research. Schizophr.Bull. 2007; 33(3): 665-672. [PubMed: 17255119]

Addington J, Cadenhead KS, Cornblatt BA, Mathalon DH, McGlashan TH, Perkins DO, Seidman LJ, Tsuang MT, Walker EF, Woods SW, Addington JA, Cannon TD. North American Prodrome Longitudinal Study (NAPLS 2): Overview and recruitment. Schizophr. Res. 2012; 142(1-3):77-82. [PubMed: 23043872]

Alexander GC, Gallagher SA, Mascola A, Moloney RM, Stafford RS. Increasing off-label use of antipsychotic medications in the United States, 1995-2008. Pharmacoepidemiol. Drug Safety. 2011; 20(2):177-184.

Amminger GP, Schafer MR, Papageorgiou K, Klier CM, Cotton SM, Harrigan SM, Mackinnon A, McGorry PD, Berger GE. Long-chain omega-3 fatty acids for indicated prevention of psychotic disorders: a randomized, placebo-controlled trial. Arch. Gen. Psychiatry. 2010; 67(2):146-154. [PubMed: 20124114]

Busch SH, Barry CL. Pediatric antidepressant use after the black-box warning. Health Aff. (Millwood). 2009; 28(3):724-733. [PubMed: 19414881]

Cadenhead KS, Addington J, Cannon T, Cornblatt B, McGlashan T, Perkins D, Seidman L, Tsuang M, Walker E, Woods S, Heinssen R. Treatment history in the psychosis prodrome: characteristics of the North American Prodrome Longitudinal Study Cohort. Early. Interv. Psychiatry. 2010; 4(3): 220-226. [PubMed: 20712727]

Carpenter WT, van Os J. Should Attenuated Psychosis Syndrome be a DSM-5 diagnosis? Am. J. Psychiatry. 2011; 168(5):460-463. [PubMed: 21536700]

Christian, R.; Saavedra, L.; Gaynes, BN.; Sheitman, B.; Wines, RCM.; Jonas, DE.; Viswanathan, M.; Ellis, AR.; Woodell, C.; Carey, TS. Agency for Healthcare Research and Quality U.S. Department of Health and Human Services; 2012. Future research needs for first- and second-generation antipsychotics for children and young adults. AHRQ Publication No. 12-EHC042-EF, http:// www.ncbi.nlm.nih.gov/books/NBK84660/pdf/TOC.pdf

Cohen D, Bonnot O, Bodeau N, Consoli A, Laurent C. Adverse Effects of Second-Generation Antipsychotics in Children and Adolescents A Bayesian Meta-Analysis. J. Clin. Psychopharmacology. 2012; 32(3):309-316.

Correll CU, Manu P, Olshanskiy V, Napolitano B, Kane JM, Malhotra AK. Cardiometabolic risk of second-generation antipsychotic medications during first-time use in children and adolescents. Jama. 2009; 302(16):1765-1773. [PubMed: 19861668]

De Hert M, Dobbelaere M, Sheridan EM, Cohen D, Correll CU. Metabolic and endocrine adverse effects of second-generation antipsychotics in children and adolescents: A systematic review of randomized, placebo controlled trials and guidelines for clinical practice. Eur. Psychiatry. 2011; 26(3):144-158. [PubMed: 21295450]

Frances, A. The scandalous off-label use of antipsychotics in anxiety disorders: Yet another warning for DSM-5, PsychologyToday.com. 2011.

Fusar-Poli P, Bonoldi I, Yung AR, Borgwardt S, Kempton MJ, Valmaggia L, Barale F, Caverzasi E, McGuire P. Predicting psychosis: Meta-analysis of transition outcomes in individuals at high clinical risk. Arch. Gen. Psychiatry. 2012a; 69(3):220-229. [PubMed: 22393215]

Fusar-Poli P, Borgwardt S, Bechdolf A, Addington J, Riecher-Rossler A, Schultze-Lutter F, Keshavan M, Wood S, Ruhrmann S, Seidman LJ, Valmaggia L, Cannon T, Velthorst E, De Haan L, Cornblatt B, Bonoldi I, Birchwood M, McGlashan T, Carpenter W, McGorry P, Klosterkotter J, McGuire P, Yung A. The psychosis high-risk state: A comprehensive state-of-the-art review. Jama Psychiatry. 2013; 70(1):107-120. [PubMed: 23165428] 
Fusar-Poli P, Deste G, Smieskova R, Barlati S, Yung AR, Howes O, Stieglitz R-D, Vita A, McGuire P, Borgwardt S. Cognitive functioning in prodromal psychosis A meta-analysis. Arch. Gen. Psychiatry. 2012b; 69(6):562-571. [PubMed: 22664547]

Gebhardt S, Haberhausen M, Heinzel-Gutenbrunner M, Gebhardt N, Remschmidt H, Krieg JC, Hebebrand J, Theisen FM. Antipsychotic-induced body weight gain: Predictors and a systematic categorization of the long-term weight course. J. Psychiatr. Res. 2009; 43(6):620-626. [PubMed: 19110264]

Giuliano AJ, Li H, Mesholam-Gately RI, Sorenson SM, Woodberry KA, Seidman LJ. Neurocognition in the psychosis risk syndrome: A quantitative and qualitative review. Curr. Pharm. Des. 2012; 18(4):399-415. [PubMed: 22239571]

Hawkins KA, McGlashan TH, Quinlan D, Miller TJ, Perkins DO, Zipursky RB, Addington J, Woods SW. Factorial structure of the Scale of Prodromal Symptoms. Schizophr. Res. 2004; 68(2-3):339347. [PubMed: 15099615]

Klosterkoetter J, Schultze-Lutter F, Bechdolf A, Ruhrmann S. Prediction and prevention of schizophrenia: what has been achieved and where to go next? World Psychiatry. 2011; 10(3):165174. [PubMed: 21991266]

Kryzhanovskaya LA, Xu W, Millen BA, Acharya N, Jen KY, Osuntokun O. Comparison of LongTerm (At Least 24 Weeks) Weight Gain and Metabolic Changes Between Adolescents and Adults Treated with Olanzapine. J. Child Adol. Psychopharmacol. 2012; 22(2):157-165.

Lemos S, Vallina O, Fernandez P, Ortega JA, Garcia P, Gutierrez A, Garcia A, Bobes J, Miller T. Predictive validity of the Scale of Prodromal Symptoms (SOPS). Actas Espanolas De Psiquiatria. 2006; 34(4):216-223. [PubMed: 16823681]

Lencz T, Smith CW, Auther A, Correll CU, Cornblatt B. Nonspecific and attenuated negative symptoms in patients at clinical high-risk for schizophrenia. Schizophr. Res. 2004; 68(1):37-48. [PubMed: 15037338]

Lencz T, Smith CW, Auther AM, Correll CU, Cornblatt BA. The assessment of "prodromal schizophrenia": Unresolved issues and future directions. Schizophr. Bull. 2003; 29(4):717-728. [PubMed: 14989409]

Maher AR, Maglione M, Bagley S, Suttorp M, Hu J-H, Ewing B, Wang Z, Timmer M, Sultzer D, Shekelle PG. Efficacy and comparative effectiveness of atypical antipsychotic medications for offlabel uses in adults: A systematic review and meta-analysis. Jama. 2011; 306(12):1359-1369. [PubMed: 21954480]

McGlashan, TH.; Walsh, BC.; Woods, SW. The Psychosis-Risk Syndrome: Handbook for Diagnosis and Follow-up. Oxford University Press; New York: 2010.

McGlashan TH, Zipursky RB, Perkins D, Addington J, Miller T, Woods SW, Hawkins KA, Hoffman RE, Preda A, Epstein I, Addington D, Lindborg S, Trzaskoma Q, Tohen M, Breier A. Randomized, double-blind trial of olanzapine versus placebo in patients prodromally symptomatic for psychosis. Am. J. Psychiatry. 2006; 163(5):790-799. [PubMed: 16648318]

McGorry PD, Yung AF, Phillips LJ, Yuen HP, Francey S, Cosgrave EM, Germano D, Bravin J, Adlard S, McDonald T, Blair A, Adlard S, Jackson H. Randomized controlled trial of interventions designed to reduce the risk of progression to first-episode psychosis in a clinical sample with subthreshold symptoms. Arch. Gen. Psychiatry. 2002; 59:921-928. [PubMed: 12365879]

Miller TJ, McGlashan TH, Rosen JL, Cadenhead K, Cannon T, Ventura J, McFarlane W, Perkins DO, Pearlson GD, Woods SW. Prodromal assessment with the structured interview for prodromal syndromes and the scale of prodromal symptoms: predictive validity, interrater reliability, and training to reliability. Schizophr. Bull. 2003; 29(4):703-715. [PubMed: 14989408]

Miller TJ, McGlashan TH, Rosen JL, Somjee L, Markovich PJ, Stein K, Woods SW. Prospective diagnosis of the initial prodrome for schizophrenia based on the Structured Interview for Prodromal Syndromes: preliminary evidence of interrater reliability and predictive validity. Am. J. Psychiatry. 2002; 159(5):863-865. [PubMed: 11986145]

Olfson M, Blanco C, Liu S-M, Wang S, Correll CU. National trends in the office-based treatment of children, adolescents, and adults with antipsychotics. Arch. Gen. Psychiatry. 2012; 69(12):12471256. [PubMed: 22868273] 
Preda A, Miller TJ, Rosen JL, Somjee L, McGlashan TH, Woods SW. Treatment histories of patients with a syndrome putatively prodromal to schizophrenia. Psychiatr. Serv. 2002; 53(3):342-344. [PubMed: 11875232]

Pringsheim T, Lam D, Patten SB. The Pharmacoepidemiology of Antipsychotic Medications for Canadian Children and Adolescents: 2005-2009. J. Child Adol. Psychopharmacol. 2011; 21(6): 537-543.

Radua J, Borgwardt S, Crescini A, Mataix-Cols D, Meyer-Lindenberg A, McGuire PK, Fusar-Poli P. Multimodal meta-analysis of structural and functional brain changes in first episode psychosis and the effects of antipsychotic medication. Neurosci. Biobehav. Rev. 2012; 36(10):2325-2333. [PubMed: 22910680]

Regier, D. quoted in Maxmen, A., Psychosis risk syndrome excluded from DSM-5: Benefits of catching psychosis early are deemed to come at too high a price, Nature.com. 2012.

Rosen JL, Miller TJ, D’Andrea JT, McGlashan TH, Woods SW. Comorbid diagnoses in patients meeting criteria for the schizophrenia prodrome. Schizophr. Res. 2006; 85(1-3):124-131. [PubMed: 16650735]

Ruhrmann S, Bechdolf A, Kuhn KU, Wagner M, Schultze-Lutter F, Janssen B, Maurer K, Hafner H, Gaebel W, Moller HJ, Maier W, Klosterkotter J. Acute effects of treatment for prodromal symptoms for people putatively in a late initial prodromal state of psychosis. Br. J. Psychiatry Suppl. 2007; 51:s88-95. [PubMed: 18055944]

Ruhrmann S, Schultze-Lutter F, Klosterkotter J. Probably at-risk, but certainly ill--advocating the introduction of a psychosis spectrum disorder in DSM-V. Schizophr. Res. 2010; 120(1-3):23-37. [PubMed: 20400269]

Safer DJ. Age-Grouped Differences in Adverse Drug Events from Psychotropic Medication. J. Child Adol. Psychopharmacol. 2011; 21(4):299-309.

Seidman LJ, Giuliano AJ, Meyer EC, Addington J, Cadenhead KS, Cannon TD, McGlashan TH, Perkins DO, Tsuang MT, Walker EF, Woods SW, Bearden CE, Christensen BK, Hawkins K, Heaton R, Keefe RS, Heinssen R, Cornblatt BA. Neuropsychology of the prodrome to psychosis in the NAPLS consortium: relationship to family history and conversion to psychosis. Arch. Gen. Psychiatry. 2010; 67(6):578-588. [PubMed: 20530007]

Smith M, Hopkins D, Peveler RC, Holt RIG, Woodward M, Ismail K. First- V. second-generation antipsychotics and risk for diabetes in schizophrenia: systematic review and meta-analysis. $\mathrm{Br}$. J. Psychiatry. 2008; 192(6):406-411. [PubMed: 18515889]

Stafford MR, Jackson H, Mayo-Wilson E, Morrison AP, Kendall T. Early interventions to prevent psychosis: systematic review and meta-analysis (vol 346, f185, 2013). Br. Med. J. 2013; 346

Walker EF, Cornblatt BA, Addington J, Cadenhead KS, Cannon TD, McGlashan TH, Perkins DO, Seidman LJ, Tsuang MT, Woods SW, Heinssen R. The relation of antipsychotic and antidepressant medication with baseline symptoms and symptom progression: a naturalistic study of the North American Prodrome Longitudinal Sample. Schizophr. Res. 2009; 115(1):50-57. [PubMed: 19709859]

Woods SW. Chlorpromazine equivalent doses for the newer atypical antipsychotics. J. Clin. Psychiatry. 2003; 64(6):663-667. [PubMed: 12823080]

Woods SW, Addington J, Cadenhead KS, Cannon TD, Cornblatt BA, Heinssen R, Perkins DO, Seidman LJ, Tsuang MT, Walker EF, McGlashan TH. Validity of the prodromal risk syndrome for psychosis: findings from North American Prodrome Longitudinal Study. Schizophr. Bull. 2009; 35:894-908. [PubMed: 19386578]

Woods SW, Breier A, Zipursky RB, Perkins DO, Addington J, Miller TJ, Hawkins KA, Marquez E, Lindborg SR, Tohen M, McGlashan TH. Randomized trial of olanzapine versus placebo in the symptomatic acute treatment of the schizophrenic prodrome. Biol. Psychiatry. 2003; 54(4):453464. [PubMed: 12915290]

Woods SW, Martin A, Spector SG, McGlashan TH. Effects of development on olanzapine-associated adverse events. J. Am. Acad. Child Adol. Psychiatry. 2002; 41(12):1439-1446.

Woods SW, Miller TJ, McGlashan TH. The "prodromal" patient: both symptomatic and at-risk. CNS Spectrums. 2001; 6(3):223-232. [PubMed: 16951657] 
Woods SW, Morgenstern H, Saksa JR, Walsh BC, Sullivan MC, Money R, Hawkins KA, Gueorguieva $\mathrm{RV}$, Glazer WM. Incidence of tardive dyskinesia with atypical and conventional antipsychotics: prospective cohort study. J. Clin. Psychiatry. 2010a; 71:463-474. [PubMed: 20156410]

Woods SW, Tully EM, Walsh BC, Hawkins KA, Callahan JL, Cohen SJ, Mathalon DH, Miller TJ, McGlashan TH. Aripiprazole in the treatment of the psychosis prodrome: an open label pilot study. Br J Psychiatry. 2007; 191(suppl 51):s96-s101.

Woods SW, Walsh BC, Saksa JR, McGlashan TH. The case for including Attenuated Psychotic Symptoms Syndrome in DSM-5 as a psychosis risk syndrome. Schizophr. Res. 2010b; 123:199_ 207. [PubMed: 20832249]

Woods SW, Ziedonis DM, Sernyak MJ, Diaz E, Rosenheck RA. Characteristics of participants and nonparticipants in medication trials for treatment of schizophrenia. Psychiatr. Serv. 2000; 51(1): 79-84. [PubMed: 10647137]

Yung AR, McGorry PD. The prodromal phase of first-episode psychosis: past and current conceptualizations. Schizophr. Bull. 1996a; 22(2):353-370. [PubMed: 8782291]

Yung AR, McGorry PD, McFarlane CA, Jackson HJ, Patton GC, Rakkar A. Monitoring and care of young people at incipient risk of psychosis. Schizophr. Bull. 1996b; 22(2):283-303. [PubMed: 8782287]

Yung AR, Phillips LJ, Nelson B, Francey SM, PanYuen H, Simmons MB, Ross ML, Kelly D, Baker K, Amminger GP, Berger G, Thompson AD, Thampi A, McGorry PD. Randomized controlled trial of interventions for young people at ultra high risk for psychosis: 6-month analysis. J. Clin. Psychiatry. 2011; 72(4):430-440. [PubMed: 21034687]

Zuddas A, Zanni R, Usala T. Second generation antipsychotics (SGAs) for non-psychotic disorders in children and adolescents: A review of the randomized controlled studies. Eur. Neuropsychopharmacology. 2011;21(8):600-620. 
Table 1

Rates of current psychotropic medication use at baseline in NAPLS-1 and NAPLS-2.

\begin{tabular}{|l|c|c|}
\hline Medication Type & $\begin{array}{c}\text { NAPLS-1 } \\
\mathbf{1 9 9 8 - 2 0 0 5} \\
(\mathbf{n = 3 9 1})\end{array}$ & $\begin{array}{c}\text { NAPLS-2 } \\
\text { First Half } \\
\mathbf{2 0 0 8}-2011 \\
(\mathbf{n = 3 4 6})\end{array}$ \\
\hline Any Psychotropic & $160(40.9 \%)$ & $141(40.8 \%)$ \\
\hline Any Antipsychotic & $44(11.3 \%)$ & $62(17.9 \%)$ \\
\hline Any Antidepressant & $119(30.4 \%)$ & $95(27.5 \%)$ \\
\hline Any Stimulant & $25(6.4 \%)$ & $18(5.2 \%)$ \\
\hline Any Mood Stabilizer & $14(3.6 \%)$ & $14(4.0 \%)$ \\
\hline Any Benzodiazepine & $17(4.3 \%)$ & $25(7.2 \%)$ \\
\hline$>1$ Class & $51(13.0 \%)$ & $58(16.8 \%)$ \\
\hline
\end{tabular}

all sites included. 
Table 2

Demographic and diagnostic characteristics at four qualifying sites*.

\begin{tabular}{|l|c|c|c|c|c|}
\hline Measure & $\begin{array}{c}\text { NAPLS-1 } \\
\mathbf{1 9 9 8 - 2 0 0 5} \\
\text { N=177 }\end{array}$ & $\begin{array}{c}\text { NAPLS-2 } \\
\text { First-Half } \\
\mathbf{2 0 0 8 - 2 0 1 1} \\
\mathbf{N = 1 7 6}\end{array}$ & $\mathrm{X}^{\mathbf{2}}$ or Z & $\mathbf{d f}$ & $\mathbf{p}$ \\
\hline Site & & & 10.3 & 3 & 0.016 \\
\hline UCLA & $34(19.2 \%)$ & $50(28.4 \%)$ & 4.1 & 1 & 0.042 \\
\hline Emory & $37(20.9 \%)$ & $47(26.7 \%)$ & 1.6 & 1 & 0.201 \\
\hline Hillside & $46(26.0 \%)$ & $43(24.4 \%)$ & 0.1 & 1 & 0.760 \\
\hline UCSD & $60(33.9 \%)$ & $36(20.5 \%)$ & 8.1 & 1 & 0.005 \\
\hline Age, median (range) & $16.3(11.8-30.3)$ & $18.0(12.0-33.0)$ & 2.2 & na & 0.000 \\
\hline No. with age < 18 & $121(68.4 \%)$ & $82(46.6 \%)$ & 17.1 & 1 & 0.003 \\
\hline No. male & $108(61.0 \%)$ & $107(60.8 \%)$ & 0.0 & 1 & 0.966 \\
\hline Race & & & 37.4 & 5 & 0.000 \\
\hline American Indian & $0(0 \%)$ & $4(2.3 \%)$ & 3.9 & 1 & 0.047 \\
\hline Asian & $10(5.8 \%)$ & $14(8.0 \%)$ & 0.6 & 1 & 0.439 \\
\hline Pacific Islander & $1(0.4 \%)$ & $3(1.7 \%)$ & 1.0 & 1 & 0.329 \\
\hline African American & $20(11.7 \%)$ & $27(15.3 \%)$ & 1.0 & 1 & 0.321 \\
\hline Caucasian & $127(74.3 \%)$ & $80(45.5 \%)$ & 29.9 & 1 & 0.000 \\
\hline Mixed Race & $13(7.6 \%)$ & $48(27.3 \%)$ & 23.2 & 1 & 0.000 \\
\hline Parental education & $6.0(1-8)$ & $6.0(1-8)$ & 0.4 & na & 0.998 \\
\hline Global functioning & $49.0(10-99)$ & $45.0(18-80)$ & 1.3 & na & 0.072 \\
\hline Inclusion diagnosis SPD & $28(15.8 \%)$ & $12(6.8 \%)$ & 7.1 & 1 & 0.008 \\
\hline DSM-IV bipolar disorder & $3(1.7 \%)$ & $16(9.5 \%)$ & 10.1 & 1 & 0.002 \\
\hline DSM-IV nonBP depression & $95(53.7 \%)$ & $66(39.1 \%)$ & 7.4 & 1 & 0.006 \\
\hline DSM-IV anxiety disorder & $69(39.0 \%)$ & $78(46.2 \%)$ & 1.8 & 1 & 0.177 \\
\hline DSM-IV ADD & $34(22.8 \%)$ & $18(10.7 \%)$ & 8.6 & 1 & 0.003 \\
\hline
\end{tabular}

* patients with baseline medication data. Qualifying sites (UCLA, Emory, Hillside, UCSD) collected data in both cohorts and did not exclude patients on antipsychotic in either. Sample size for race in NAPLS-1 was 171. Sample size for comorbid diagnoses was 169 in NAPLS-2 and for ADD in NAPLS-1 149.

Z--Kolmogorov-Smirnov Z statistic. na-- not applicable. SPD--schizotypal personality disorder. nonBP--nonbipolar. ADD--attention deficit disorder. 
Table 3

Comparison of baseline psychotropic medication use at qualifying sites in NAPLS-1 and NAPLS-2.

\begin{tabular}{|c|c|c|c|c|}
\hline \multirow{2}{*}{ Medication Type } & \multirow{2}{*}{$\begin{array}{c}\text { NAPLS-1 } \\
\text { 1998-2005 } \\
(\mathrm{n}=177)\end{array}$} & \multirow{2}{*}{$\begin{array}{c}\text { NAPLS-2 } \\
\text { First Half } \\
\text { 2008-2011 } \\
(\mathrm{n}=176)\end{array}$} & \multicolumn{2}{|c|}{ Rate Ratio $(95 \% \text { CI })^{I}$} \\
\hline & & & Unadjusted & Adjusted $^{2}$ \\
\hline Any Psychotropic & $95(53.7 \%)$ & $68(38.6 \%)$ & $0.72(0.54,0.91)$ & $0.79(0.60,0.99)$ \\
\hline Any Antipsychotic & $43(24.3 \%)$ & $31(17.6 \%)$ & $0.73(0.47,1.09)$ & $0.66(0.41,1.02)$ \\
\hline Any Antidepressant & $62(35.0 \%)$ & $39(22.2 \%)$ & $0.63(0.43,0.89)$ & $0.70(0.45,1.01)$ \\
\hline Any Stimulant & $19(10.7 \%)$ & $8(4.5 \%)$ & $0.42(0.19,0.94)$ & $0.42(0.11,1.50)$ \\
\hline Any Mood Stabilizer & $12(6.8 \%)$ & $10(5.7 \%)$ & $0.84(0.36,1.84)$ & $0.72(0.27,1.82)$ \\
\hline Any Benzodiazepine & $9(5.1 \%)$ & $11(6.3 \%)$ & $1.23(0.52,2.79)$ & $1.17(0.48,2.70)$ \\
\hline$>1$ Class & $42(23.7 \%)$ & $22(12.5 \%)$ & $0.53(0.32,0.85)$ & $0.56(0.32,0.93)$ \\
\hline
\end{tabular}

qualifying sites defined as per Table 2.

CI -- confidence interval.

1

rate ratio for baseline prescription in NAPLS-2 relative to NAPLS-1.

models adjusted by inclusion as covariates of characteristics from Table S4 significantly associated with prescription at the p $<0.05$ level. 
Table 4

Individual antipsychotic medications at baseline in NAPLS-1 and NAPLS-2.

\begin{tabular}{|l|c|c|c|c|c|}
\hline $\begin{array}{l}\text { Antipsychotic } \\
\text { Medication }\end{array}$ & $\begin{array}{c}\text { NAPLS-1 } \\
\mathbf{1 9 9 8 - 2 0 0 5} \\
(\mathbf{n = 4 4 )}\end{array}$ & $\begin{array}{c}\text { NAPLS-2 } \\
\text { First Half } \\
\mathbf{2 0 0 8 - 2 0 1 1} \\
(\mathbf{n = 6 2})\end{array}$ & $\mathrm{X}^{2}$ & $\mathbf{d f}$ & $\mathbf{p}$ \\
\hline Aripiprazole & $3(6.8 \%)$ & $27(43.5 \%)$ & 17.1 & 1 & 0.000 \\
\hline Risperidone & $24(54.5 \%)$ & $15(24.2 \%)$ & 10.2 & 1 & 0.001 \\
\hline Quetiapine & $7(15.9 \%)$ & $11(17.7 \%)$ & 0.1 & 1 & 0.804 \\
\hline Olanzapine & $11(25.0 \%)$ & $6(9.7 \%)$ & 4.5 & 1 & 0.034 \\
\hline Ziprasidone & $3(6.8 \%)$ & $3(4.8 \%)$ & 0.2 & 1 & 0.664 \\
\hline Haloperidol & $0(0 \%)$ & $1(1.6 \%)$ & 0.7 & 1 & 0.397 \\
\hline$>1$ Antipsychotic & $4(9.1 \%)$ & $1(1.6 \%)$ & 3.2 & 1 & 0.074 \\
\hline
\end{tabular}

all sites included. 


\section{Table 5}

Antipsychotic dose in mg/d for specific medications at baseline and chlorpromazine-equivalent dose for any antipsychotic medication at baseline in NAPLS-2.

\begin{tabular}{|l|c|c|c|c|}
\hline Antipsychotic Medication & Mean & Min & Max & SD \\
\hline Aripiprazole (n=26) $^{l}$ & 7.8 & 2.0 & 30.0 & 6.4 \\
\hline Risperidone (n=14) $^{l}$ & 1.7 & 0.5 & 4.0 & 1.0 \\
\hline Quetiapine (n=10) $^{l}$ & 121 & 3 & 300 & 111 \\
\hline Olanzapine (n=6) $^{1}$ & 7.5 & 2.5 & 17.5 & 5.7 \\
\hline Ziprasidone (n=2) $^{l}$ & 100 & 80 & 120 & 28 \\
\hline Haloperidol (n=1) & 10.0 & 10.0 & 10.0 & -- \\
\hline Any antipsychotic (n=58) & 121 & 4 & 500 & 108 \\
\hline
\end{tabular}

*all sites included.

1 one subject missing baseline dose. 
Table 6

Lifetime months of exposure to baseline psychotropic medication in NAPLS-2.

\begin{tabular}{|l|c|c|c|c|}
\hline Medication Type & Mean & Min & Max & SD \\
\hline Any psychotropic $(\mathrm{n}=141)$ & 24.9 & 0.03 & 174.5 & 35.7 \\
\hline Antipsychotic $(\mathrm{n}=62)$ & 3.8 & 0.03 & 37.8 & 5.9 \\
\hline Antidepressant $(\mathrm{n}=95)$ & 17.9 & 0.03 & 155.4 & 26.9 \\
\hline Stimulant $(\mathrm{n}=18)$ & 64.8 & 3.7 & 156.4 & 43.8 \\
\hline Mood stabilizer $(\mathrm{n}=14)$ & 17.6 & 0.20 & 53.8 & 17.6 \\
\hline Benzodiazepine $(\mathrm{n}=25)$ & 10.7 & 0.13 & 88.0 & 19.0 \\
\hline
\end{tabular}

among patients receiving the medication class at baseline, all sites included. 


\section{Table 7}

Lifetime months of exposure to baseline psychotropic medication prior to the first lifetime antipsychotic dose in NAPLS-2.*

\begin{tabular}{|c|c|c|c|c|}
\hline Medication Type & Mean & Min & Max & SD \\
\hline Any psychotropic $(\mathrm{n}=36 / 62,58 \%)$ & 18.4 & 0.03 & 92.7 & 23.5 \\
\hline Antidepressant $(\mathrm{n}=30 / 62,48 \%)$ & 11.5 & 0.03 & 61.9 & 15.5 \\
\hline Stimulant $(\mathrm{n}=10 / 62,16 \%)$ & 39.2 & 0.5 & 92.7 & 29.1 \\
\hline Mood stabilizer $(n=3 / 62,5 \%)$ & 4.0 & 1.5 & 7.3 & 3.0 \\
\hline Benzodiazepine $(\mathrm{n}=5 / 62,8 \%)$ & 1.3 & 0.5 & 2.5 & 0.9 \\
\hline No prior psychotropic $(n=26 / 62,42 \%)$ & 0 & 0 & 0 & 0 \\
\hline
\end{tabular}

